\title{
Management of intra-operative acute pulmonary embolism during general anesthesia: a case report
}

\author{
Yuanyuan Mao', Shuai Wen², Gezi Chen', Wei Zhang ${ }^{1}$, Yanqiu $\mathrm{Ai}^{1}$ and Jingjing Yuan ${ }^{1 *}$ (D)
}

\begin{abstract}
Background: Acute pulmonary embolism (APE) can be life-threatening. Early detection is even more difficult for patients under general anesthesia as common symptoms are not available and the pathophysiological course of intra-operative APE is influenced by procedures of surgery and anesthesia, which makes patients under general anesthesia a distinctive group.

Case presentation: We report a case of APE during orthopedic surgery under general anesthesia. A 64-year-old female with atrial fibrillation and surgical history of varicosity underwent total right hip replacement surgery under general anesthesia. No arterial or deep vein thrombosis (DVT) was found prior to the surgery, but APE still occurred intraoperatively. The sudden decrease in $\mathrm{P}_{\mathrm{ET}} \mathrm{CO}_{2}$ and increase in $\mathrm{PaCO}_{2}$ combined other clues raised the suspect of APE, which is further evidenced by transesophageal echocardiogram (TEE). Multidisciplinary consultation was started immediately. After discussion with the consultation team and communication with patient's family members, anticoagulation therapy was started and IVC filter was placed to prevent PE recurrence. The patient went through the operation and discharged uneventfully 30 days later.
\end{abstract}

Conclusions: Pulmonary embolism is a rare and potentially high-risk perioperative situation, with a difficult diagnosis when occurs under anesthesia. The separation phenomenon of decrease in $\mathrm{PETCO}_{2}$ and increase in $\mathrm{PaCO}_{2}$ might be a useful and suggestive sign, enabling prompt management and therefore improving the prognosis.

Keywords: Intra-operation, Acute pulmonary embolism, General anesthesia, Multidisciplinary consultation

\section{Background}

Acute pulmonary embolism (APE) remains a significant medical problem, relating to more than 300,000 deaths per year in Europe [1]. Early detection and treatment are vital for a better prognosis [2]. Signs and symptoms such as dyspnea, chest pain, hemoptysis and syncope could be clues for APE detection [3, 4]. But they are not available for patients under general anesthesia, which increases the difficulty for early diagnosis and stresses the need for other indications. Moreover, the pathophysiologic course of intraoperative APE is affected by procedures of operation and anesthesia, which might be different from conscious patients with spontaneous respiration. The following report describes a case of APE during hip

\footnotetext{
*Correspondence: yjingjing_99@163.com

'Department of Anesthesiology, First Affiliated Hospital of Zhengzhou

University, No.1 East-JianShe Road, Zhengzhou 450052, China

Full list of author information is available at the end of the article
}

replacement surgery, that provides us with a meaningful phenomenon-an opposite trend in increased $\mathrm{PaCO}_{2}$ and decreased $\mathrm{P}_{\mathrm{ET}} \mathrm{CO}_{2}$-as an early sign of potential APE for patients undergoing general anesthesia and mechanical ventilation.

\section{Case presentation}

A 64-year-old, BMI $32.7 \mathrm{~kg} / \mathrm{m}^{2}$, American Society of Anesesthesiolgists (ASA) physical status III, female was scheduled for right hip replacement because of bone fracture. She received a surgery for bilateral lower extremity varicose veins 8 years ago and recovered well. There is no past medical history of hypertension, diabetes mellitus or cerebrovascular diseases. Patient had no drug or food allergies, never smoked cigarettes or consumed alcohol.

Chest X-ray showed heart shadow enlargement (cardiothoracic ratio: 0.65) and slight pleural effusion left 
side. Echocardiogram showed bilateral atrial dilatation, atrial fibrillation, slight bicuspid and tricuspid regurgitation, right pulmonary mild hypertension (pulmonary arterial systolic pressure: $51 \mathrm{mmHg}$ ) and a decreased systolic function of left ventricular. ECG showed acceleration of ventricular rate, atrial fibrillation and $\mathrm{T}$ wave non specific changes. D-dimer was $2.517 \mu \mathrm{g} / \mathrm{ml}$ (normal: $0-0.3 \mu \mathrm{g} / \mathrm{ml}$ ). Other laboratory assessments were within normal limits. Despite abnormal findings in pre-procedure tests, no uncomfortable symptoms were reported. She emphasized to be in good condition before the fracture that she could do Dama square dance for $2 \mathrm{~h}$ every day after supper. There were no complaints except for the pain due to bone fracture. She denied further examination or treatment and insisted on an operation for the fracture as soon as possible, as it reduced her life quality severely.

Therefore she was scheduled for surgery and transferred to the operating room 3 days after admission. Preoxygen and monitoring were performed, which showed BP 110/80 mmHg, HR $140 \mathrm{bpm}$ and $\mathrm{SpO}_{2}$ 98\%. Considering her anxiety and tachycardia, $10 \mathrm{mg}$ esmolol and $60 \mu \mathrm{g}$ dexmedetomidine were given intravenously in $10 \mathrm{~min}$. Soon the heart rate slowed down and stabled at $110 \mathrm{bpm}$. Arterio radialis puncture was performed for invasive blood pressure monitoring under $1 \%$ lidocaine local anesthesia. For anesthesia induction, midazolam $(0.03 \mathrm{mg} / \mathrm{kg})$, fentanyl $(4 \mu \mathrm{g} / \mathrm{kg})$, etomidate $(0.25 \mathrm{mg} / \mathrm{kg})$ and cisatracurium $(0.2 \mathrm{mg} / \mathrm{kg})$ were administered. After intubation, mechanical ventilation started with volume control model (RR:12 breaths per minute, tidal volume:6-8 ml/ $\mathrm{kg}, \mathrm{P}_{\mathrm{ET}} \mathrm{CO}_{2}: 35-45 \mathrm{mmHg}$ ). General anesthesia was maintained with sevoflurane (1\%), propofol $(4-10 \mathrm{mg} / \mathrm{kg} / \mathrm{h})$, remifentanil $(0.1-0.2 \mu \mathrm{g} / \mathrm{kg} / \mathrm{min})$, cisatracurium $(0.1 \mathrm{mg} /$ $\mathrm{kg} / \mathrm{h})$ and dexmedetomidine $(0.5 \mu \mathrm{g} / \mathrm{kg} / \mathrm{h})$. A central venous catheter was placed in the right internal jugular vein under ultrasonic guidance in case of mass transfusion and vasoactive drugs application intraoperatively. Patient was then placed in left lateral decubitus position and the operation began.

Approximately $1 \mathrm{~h}$ later, when the surgery was almost finished and the incision was closing, a sudden pronounced decrease in oxygen saturation $(100 \%-66 \%)$ was noticed, along with gradually increased airway pressure $\left(22-33 \mathrm{cmH}_{2} \mathrm{O}\right)$ and decrease in blood pressure (lowest to $89 / 60 \mathrm{mmHg}$ ). $\mathrm{P}_{\mathrm{ET}} \mathrm{CO}_{2}$ decreased from $34 \mathrm{mmHg}$ to $22 \mathrm{mmHg}$. ECG showed rapid atrial fibrillation (heart rate 140-160 bpm). Auscultation revealed bilateral breath sounds. Central venous pressure (CVP) was assessed immediately with a value of $30 \mathrm{cmH}_{2} \mathrm{O}$. Instant arterial blood gas analysis showed hypercapnia (Table 1). The opposite trend of $\mathrm{PaCO}_{2}$ and $\mathrm{P}_{\mathrm{ET}} \mathrm{CO}_{2}$, combined with other signs and medical history, indicated the possibility of APE. Transesophageal echocardiogram (TEE) was arranged at once, which showed
Table 1 The arterial blood gas analysis of the patient

\begin{tabular}{lcc}
\hline Parameter & $\mathrm{T} 1$ & $\mathrm{~T} 2$ \\
\hline $\mathrm{pH}$ & 7.161 & 7.231 \\
$\mathrm{pCO}_{2}(\mathrm{mmHg})$ & 66.9 & 62.7 \\
$\mathrm{pO}_{2}(\mathrm{mmHg})$ & 40.7 & 76.4 \\
$\mathrm{SO}_{2}(\%)$ & 65.9 & 92.7 \\
$\mathrm{CLac}(\mathrm{mmol} / \mathrm{L})$ & 0.6 & 0.6 \\
$\mathrm{CtO}_{2}(\mathrm{mmol} / \mathrm{L})$ & 12.6 & 17.8 \\
$\mathrm{p} 50(\mathrm{mmHg})$ & 32.19 & 31.75 \\
$\mathrm{HCO} 3 \mathrm{std}(\mathrm{mmol} / \mathrm{L})$ & 18.3 & 21.8 \\
$\mathrm{HCO} 3^{-}(\mathrm{mmol} / \mathrm{L})$ & 22.9 & 25.3 \\
$\mathrm{ABE}(\mathrm{mmol} / \mathrm{L})$ & -6.8 & -3.1 \\
$\mathrm{SBE}(\mathrm{mmol} / \mathrm{L})$ & -4.6 & -1.3 \\
\hline
\end{tabular}

T1: the time point when respiratory and hemodynamic changes occurred. T2: the time point when the patient's condition became stable. T2 time point was $9 \mathrm{~min}$ after the T1 time point

enlargement of the right atrial, abnormal echoic area in pulmonary artery (considering thrombus) and pulmonary hypertension (pulmonary arterial systolic pressure: $77 \mathrm{mmHg}$ ) (Additional file 1: Movie S1).

Multidisciplinary consultation started simultaneously. Mechanical and manual ventilation were controlled alternately. Cedilanid $(0.2 \mathrm{mg})$, phenylephrine $(0.03-$ $0.06 \mathrm{mg} / \mathrm{kg} / \mathrm{min}), 5 \% \mathrm{NaHCO}_{3}$ liquid $(100 \mathrm{ml})$ and methylprednisolone $(500 \mathrm{mg})$ were administered intravenously to maintain hemodynamic stability and improve internal environment. All fluids were limited to reduce the cardiac load. 11 min later, $\mathrm{SpO}_{2}$ increased to $95 \%$ and $\mathrm{BP}$ rose to $120 / 80 \mathrm{mmHg}$. A following systematic ultrasound examination revealed deep venous thrombosis, which was not found before the surgery and might be the source of pulmonary embolism. After discussion with surgical and respiratory consultation team and communication with the patient's family members, low molecular weight heparin calcium(LMWHC) (6000 IU) was given and inferior vena cava (IVC) filter was implanted in DSA operating room. After surgery, the patient was transferred to ICU intubated. Patient recovered her consciousness $3 \mathrm{~h}$ later and extubated the next morning. Further treatment including anticoagulation, alleviation of pulmonary hypertension and atrial fibrillation therapy was continued. IVC filter was removed 20 days later. Her condition was improved and all vital signs maintained stable. The patient was discharged from hospital uneventfully one month later.

\section{Discussion}

Here we described a case of intra-operative APE and reported a meaningful sign -"separation phenomenon" during general anesthesia, which means a decrease trend in $\mathrm{P}_{\mathrm{ET}} \mathrm{CO}_{2}$ and increase in $\mathrm{PaCO}_{2}$. This is different from 
conscious patients with incomplete obstruction of pulmonary artery, whose physiological dead space increases and total minute ventilation increases correspondingly. In these patients, $\mathrm{PaCO}_{2}$ is mostly lower than normal because of the compensatory mechanism. However, this mechanism does not work under general anesthesia and mechanical ventilation. Thus when APE occurred in patients with mechanical ventilation, $\mathrm{P}_{\mathrm{ET}} \mathrm{CO}_{2}$ does not actually reflect $\mathrm{PaCO}_{2}$ anymore. In fact, the difference of $\mathrm{PaCO}_{2}$ and $\mathrm{P}_{\mathrm{ET}} \mathrm{CO}_{2}$ could be a representative of dead space, which has been studied as a tool to monitor the effect of thrombolysis [5]. Beside dead space increase, low cardiac output and ventilation-perfusion mismatch also contribute to the hypoxemia and hypercapnia [6]. Though not pathognomonic, the separation phenomenon is still valuable. Just like chest pain and dyspnea, these symptoms are not specific, but in a similar context to our case, could be highly suggestive. $\mathrm{P}_{\mathrm{ET}} \mathrm{CO}_{2}$ is a routine monitoring under general anesthesia and arterial blood analysis is a quick bedside test. Thus we suggest strict monitoring of $\mathrm{P}_{\mathrm{ET}} \mathrm{CO}_{2}$ and arterial blood analysis especially when $\mathrm{P}_{\mathrm{ET}} \mathrm{CO}_{2}$ decreases without other reasons during general anesthesia. When the separation phenomenon occurred, PE should be taken into consideration.

We suspected venous thrombus that led to APE in this patient. First, she had a surgical history of varicosity. Although no thrombus was found before the surgery, it was a risk factor of pulmonary thromboembolism. Second, intraoperative TEE showed abnormal echoic area in pulmonary artery (considering thrombus) and the following systematic ultrasound examination revealed deep venous thrombosis. The most common cause of PE remains deep vein thrombosis [7]. Finally, anti-coagulation therapy was useful to improve the condition.

The initial clinical symptoms in this case could also suggest a pneumothorax. But there was no further evidence. Procedure of central venous of catheterization might be a cause for pneumothorax. But the process was guided by ultrasound without any abnormal sign. Also, instant intraoperative auscultation confirmed bilateral breath sounds.

Since it was a hip surgery, the intra-operative APE might also be caused by cement embolus. The known bone cement implantation syndrome (BCIS) is commonly caused by PE, which is characterized by a number of clinical features such as hypoxia, hypotension, cardiac arrhythmias and increased pulmonary vascular resistance. It usually occurs at one of these stages of surgical procedure including femoral reaming, acetabular or femoral cement implantation, insertion of the prosthesis or joint reduction [8]. However, in this case, the hemodynamic changes and hypoxia presented at none of these stages but at the end of operation, when the wound was closing. There are studies showing that cement embolic events are common and most patients tolerate well [9]. Even if BCIS occurs, there is no specific treatment at present [8]. To confirm the cause of APE might need further test, like computed tomography. It was not conducted in this case, which was a pity, considering the high cost and little effect on the treatment.

Combining all the clues, the most possible reason for the hemodynamic and respiratory changes in this case was pulmonary thromboembolism. The treatment requires rapid and accurate risk assessment. Thrombolytic treatment restores pulmonary perfusion more rapidly than anticoagulation alone, but it also carries a risk of major bleeding, including intracranial hemorrhage. And the increased age and presence of comorbidity have been associated with higher risk of hemorrhage [10]. Surgery is also a relative contraindication to thrombolysis. After discussion with the consultation team and communication with patient's family members, anticoagulation therapy was started and IVC filter was placed to prevent PE recurrence. The patient finally discharged uneventfully.

The good clinical outcome could be predicted by the lactate value. Plasma lactate concentration is a sensitive marker of tissue hypoxia and persistent tissue hypoxia may cause irreversible cell injury which was associated with the adverse outcome in critically ill patients [11, 12]. Studies showed that plasma lactate was prognostic for short-term PE-related complications and high plasma lactate $(\geq 2 \mathrm{~mol} / \mathrm{L})$ was associated with increased in-hospital mortality [13-15]. Lactate concentration in this case remained at a low level which might due to our fast detection and treatment. Thus tissue hypoperfusion was temporary and reversible.

Despite updated guidelines, PE remains an important clinical problem with a high mortality rate. Even with prophylaxis, it could still happen and sometimes appeared as an emergency [16]. A flow diagram specific to intra-operative APE might be a useful aid, especially for this infrequent and high-risk situation. Also, multidisciplinary cooperation is necessary to get the most appropriate treatment strategy.

\section{Conclusion}

Pulmonary embolism is a rare and potentially high-risk perioperative situation, with a difficult diagnosis when occurs under anesthesia. The separation phenomenon of decrease in $\mathrm{P}_{\mathrm{ET}} \mathrm{CO}_{2}$ and increase in $\mathrm{PaCO}_{2}$ might be a useful and suggestive sign, enabling prompt management and therefore improving the prognosis.

\section{Additional file}

Additional file 1: Movie S1. A real-time TEE image revealed a mobile embolus in the PA. PA, pulmonary artery; Ao, aorta. (WMV 1mb) 


\section{Abbreviations}

APE: Acute pulmonary embolism; CVP: Central venous pressure; DVT: Deep vein thrombosis; IVC: Inferior vena cava; $\mathrm{P}_{\mathrm{ET}} \mathrm{CO}_{2}$ : End-tidal $\mathrm{CO}_{2}$ pressure; TEE: Transesophageal echocardiogram

\section{Acknowledgements}

We would like to thank Professor Yanli Ma, Bin Li, Yong Wang and Liwei Li for their help in the rescue.

\section{Funding}

None.

\section{Availability of data and materials}

All data and materials described in the manuscript will be freely available to any scientist wishing to use them for non-commercial purposes. Raw data are not available as all are in the patient electronic medical record. Please consider the edited data in the case report.

\section{Authors' contributions}

YM and SW contributed equally to this paper: Preparation of the manuscript. GC, WZ and YA participated in patient care. JY involved in the case and drafted the manuscript. All authors read and approved the final manuscript.

\section{Competing interests}

The authors declare that they have no competing interests.

\section{Consent for publication}

Written informed consent was obtained from the patient for publication of this case report. A copy of the written consent is available for review by the Editor of this journal.

\section{Ethics approval and consent to participate}

Not applicable.

\section{Publisher's Note}

Springer Nature remains neutral with regard to jurisdictional claims in published maps and institutional affiliations.

\section{Author details}

'Department of Anesthesiology, First Affiliated Hospital of Zhengzhou University, No.1 East-JianShe Road, Zhengzhou 450052, China. ²Department of Modern Education Technology Center, Henan Medical College, No.8 Shuanghu Road, Longhu, Zhengzhou 451191, China.

Received: 9 December 2016 Accepted: 17 May 2017

Published online: 26 May 2017

\section{References}

1. Cohen AT, Agnelli G, Anderson FA, Arcelus Jl, Bergqvist D, Brecht JG, et al. Venous thromboembolism (VTE) in Europe. The number of VTE events and associated morbidity and mortality. Thromb Haemost. 2007;98(4):756-64.

2. He J, Cheng X, Gao M. Survey of diagnosis and treatment of acute pulmonary embolism in 21 hospitals in China. Zhonghua Yi Xue Za Zhi. 2001;81(24):1490-2.

3. Wells PS, Ginsberg JS, Anderson DR, Kearon C, Gent M, Turpie AG, et al. Use of a clinical model for safe management of patients with suspected pulmonary embolism. Ann Intern Med. 1998;129(12):997-1005.

4. Prandoni $\mathrm{P}$, Lensing $\mathrm{AW}$, Prins $\mathrm{MH}$, Ciammaichella M, Perlati M, Mumoli $\mathrm{N}$, et al. Prevalence of pulmonary embolism among patients hospitalized for syncope. N Engl J Med. 2016;375(16):1524-31.

5. Wiegand UK, Kurowski V, Giannitsis E, Katus HA, Djonlagic H. Effectiveness of end-tidal carbon dioxide tension for monitoring thrombolytic therapy in acute pulmonary embolism. Crit Care Med. 2000;28(11):3588-92.

6. Goldhaber SZ, Elliott CG. Acute pulmonary embolism: part I: epidemiology, pathophysiology, and diagnosis. Circulation. 2003;108(22):2726-9.

7. Konstantinides SV, Torbicki A, Agnelli G, Danchin N, Fitzmaurice D, Galie N, et al. 2014 ESC quidelines on the diagnosis and management of acute pulmonary embolism. Eur Heart J. 2014;35(43):3033-69. 3069a

8. Donaldson AJ, Thomson HE, Harper NJ, Kenny NW. Bone cement implantation syndrome. Br J Anaesth. 2009;102(1):12-22.
9. Ereth $\mathrm{MH}$, Weber JG, Abel MD, Lennon RL, Lewallen DG, Istrup DM, et al. Cemented versus noncemented total hip arthroplasty-embolism, hemodynamics, and intrapulmonary shunting. Mayo Clin Proc. 1992;67(11):1066-74.

10. Mikkola KM, Patel SR, Parker JA, Grodstein F, Goldhaber SZ. Increasing age is a major risk factor for hemorrhagic complications after pulmonary embolism thrombolysis. Am Heart J. 1997;134(1):69-72.

11. Bakker J, Nijsten MW, Jansen TC. Clinical use of lactate monitoring in critically ill patients. Ann Intensive Care. 2013;3(1):12.

12. Shoemaker WC, Appel PL, Kram HB. Tissue oxygen debt as a determinant of lethal and nonlethal postoperative organ failure. Crit Care Med. 1988; 16(11):1117-20.

13. Vanni S, Viviani G, Baioni M, Pepe G, Nazerian P, Socci F, et al. Prognostic value of plasma lactate levels among patients with acute pulmonary embolism: the thrombo-embolism lactate outcome study. Ann Emerg Med. 2013;61(3):330-8.

14. Vanni S, Jimenez D, Nazerian P, Morello F, Parisi M, Daghini E, et al. Shortterm clinical outcome of normotensive patients with acute PE and high plasma lactate. Thorax. 2015;70(4):333-8.

15. Vanni S, Socci F, Pepe G, Nazerian P, Viviani G, Baioni M, et al. High plasma lactate levels are associated with increased risk of in-hospital mortality in patients with pulmonary embolism. Acad Emerg Med. 2011 18(8):830-5.

16. Goldhaber SZ, Visani L, De Rosa M. Acute pulmonary embolism: clinical outcomes in the international cooperative pulmonary embolism registry (ICOPER). Lancet. 1999;353(9162):1386-9.

\section{Submit your next manuscript to BioMed Central and we will help you at every step:}

- We accept pre-submission inquiries

- Our selector tool helps you to find the most relevant journal

- We provide round the clock customer support

- Convenient online submission

- Thorough peer review

- Inclusion in PubMed and all major indexing services

- Maximum visibility for your research

Submit your manuscript at www.biomedcentral.com/submit
) Biomed Central 